Check for updates

Cite this: RSC Adv., 2019, 9, 32620

Received 21st July 2019

Accepted 10th September 2019

DOI: 10.1039/c9ra05628a

rsc.li/rsc-advances

\title{
Study on the growth and morphology evolution of titanium oxide clusters in molten iron with molecular dynamics simulation
}

\begin{abstract}
Likun Yang, (D) ${ }^{a}$ Wei Zhang, ${ }^{\text {ab }}$ Liang He, ${ }^{a}$ Huigai Li ${ }^{\star a}$ and Shaobo Zheng*a
Formation of nano-scale titanium oxides is a desirable result in the deoxidation process of steelmaking. However, the nucleation of nano-scale titanium oxide inclusions remains unknown up to now because of the difficulty in observing and detecting inclusions in steel melt. In this work, we studied the formation and evolution of titanium oxygen clusters in molten iron by molecular dynamics (MD) simulation using empirical atomic interaction potentials. The structures of small titanium oxygen clusters in iron are reasonable compared to the first-principles simulation results. The growth process of small clusters into larger clusters was simulated and it is found the clusters grow through the collision mechanism, with the intermediate products exhibiting chain structures. The iron environment was found to play an important role in the structural form of the titanium oxygen clusters. This study is useful to provide the details of formation and the growth mechanism of titanium oxygen clusters and to provide a valuable picture for the nucleation mechanism of titanium oxide in molten steel.
\end{abstract}

\section{Introduction}

Titanium is a widely used deoxidizing element in molten steel. ${ }^{1}$ Titanium and dissolved oxygen react to form titanium oxide during refining in the steelmaking process. The stoichiometric ratio and structure of titanium oxides depend on the ratio of titanium and oxygen concentrations in molten steel. ${ }^{2}$ Titanium oxides with a certain size and structure are effective nucleation sites for sulfides, ${ }^{3}$ nitrides, ${ }^{4}$ and intragranular acicular ferrite. ${ }^{5}$ With the aim of effectively controlling the precipitation behaviour of this kind of favorable and fine titanium oxide, it is necessary to study the growth and morphology evolution of titanium oxide clusters in molten steel. However, it is difficult to observe the nucleation process of oxides directly through experimental approaches in molten steel because of the high temperature. We tried to use a MD simulation method to reproduce this process.

Regarding the nucleation process, the classical nucleation theory does not explain the existence of pre-nucleation clusters in liquid, but it was proved from $\mathrm{CaCO}_{3}$ solution, ${ }^{6} \mathrm{Fe}-\mathrm{O}-\mathrm{Al}$ melt, ${ }^{7-10}$ and $\mathrm{Fe}-\mathrm{O}-\mathrm{Al}-\mathrm{Mg}$ melt ${ }^{11}$ that the pre-nucleation clusters do exist and rearrange to form nuclei. In our previous work, Dan Zhao et al. ${ }^{12}$ studied the detailed nucleation process of titanium oxides in Fe-Ti rapid solidified alloy. Through atomic probe

${ }^{a}$ State Key Laboratory of Advanced Special Steel, Shanghai Key Laboratory of Advanced Ferrometallurgy, School of Materials Science and Engineering, Shanghai University, Shanghai 200444, China.E-mail: lihuigai@shu.edu.cn; sbzheng@staff.shu.edu.cn

${ }^{b}$ Shanghai Institute of Applied Physics, Chinese Academy of Sciences (CAS), Shanghai 201800, China tomography characterization, we confirmed that the nucleation of titanium oxides includes two steps: (1) "TiO" basic units aggregated and formed $(\mathrm{TiO})_{n}$ clusters; (2) O atoms were absorbed in and around the clusters and the clusters evolved into different nuclei of titanium oxides depending on the titanium and oxygen concentrations in molten steel. This is the experimental basis for the two-step nucleation of titanium oxides. Bao et al. ${ }^{13}$ proposed the possible growth pathway of titanium oxide clusters by calculating the formation energy of different (TiO) ${ }_{n}$ structures in a $4 \times 4 \times 4$ iron matrix using firstprinciples calculation. They calculated the interaction force between atoms using DFT method, but the size of the simulation systems that can be treated is limited to hundreds of atoms. Classical MD method with empirical atomic potential can treat systems of much larger size, typically up to $10^{6}-10^{9}$ atoms, thus it provides a way to investigate the growth process of pre-nucleation clusters.

Researchers mostly focused on the study of titanium oxide nanoclusters structure ${ }^{14-16}$ or titanium oxide nucleation. ${ }^{17}$ The structure and growth mechanism of titanium oxide cluster before nucleation in molten iron is obscure. In this work, the melting point of iron was normalized to determine the simulated temperature. Then the evolution of titanium oxygen $\left(\mathrm{Ti}_{x} \mathrm{O}_{y}, x\right.$ and $y$ represent the number of titanium and oxygen atoms) clusters were simulated in molten iron with titanium concentrations between $0.02 \%$ and $1.00 \%$. Cluster identification and reverse tracking of the atomic trajectory were utilized to trace the evolution of the $\mathrm{Ti}_{x} \mathrm{O}_{y}$ clusters in molten iron. Finally, we explored the effect of molten iron on the structure of $\mathrm{Ti}_{x} \mathrm{O}_{y}$ clusters, which provides a possibility to continue to 
explore the formation of the critical nucleation of titanium oxides.

\section{Method}

\subsection{Simulation setup}

All simulations were carried out using MD simulation code LAMMPS..$^{18}$ Periodic boundary condition was used and the time step for integration is $1 \mathrm{fs}$. The key factor for MD simulation is the interaction potential between atoms. To model the interaction of Ti-O system, we chose the Ti-O potential function derived from the defect oxygen in metal titanium. ${ }^{19}$ Pencer et $a l .^{20}$ used this potential to accurately predict elastic constants of hep titanium with and without interstitial oxygen solute. The $\mathrm{Fe}-\mathrm{O}$ potential function came from Zhou's result. ${ }^{21} \mathrm{Jeon}$ et al. ${ }^{22}$ employed this potential to studied the surface oxide film growth on Al-Ni-Fe alloys. Fe-Ti interaction was depicted by the potentials of EAM (embedded-atom method) format. ${ }^{23}$

\subsection{Determination of simulated temperature}

The melting temperature of iron described by the potential is essential for studying the growth and evolution of $\mathrm{Ti}_{x} \mathrm{O}_{y}$ clusters in the case of high temperature molten iron. The melting point was calculated according to Morris' method, ${ }^{24}$ the coexisting system with solid and liquid phase was established under isothermal-isobaric (NPT) ensemble, as shown in Fig. 1(a), which consists of 23040 iron atoms.

We changed the temperature and pressure to ensure that the system has solid-liquid coexistence under the microcanonical ensemble (NVE) after relaxed for $10 \mathrm{~ns}$. The temperature of the solid-liquid coexisting system was taken as the Fe-Ti-O potential melting point $\left(T_{\mathrm{pot}}\right)$. The $T_{\mathrm{pot}}$ under different
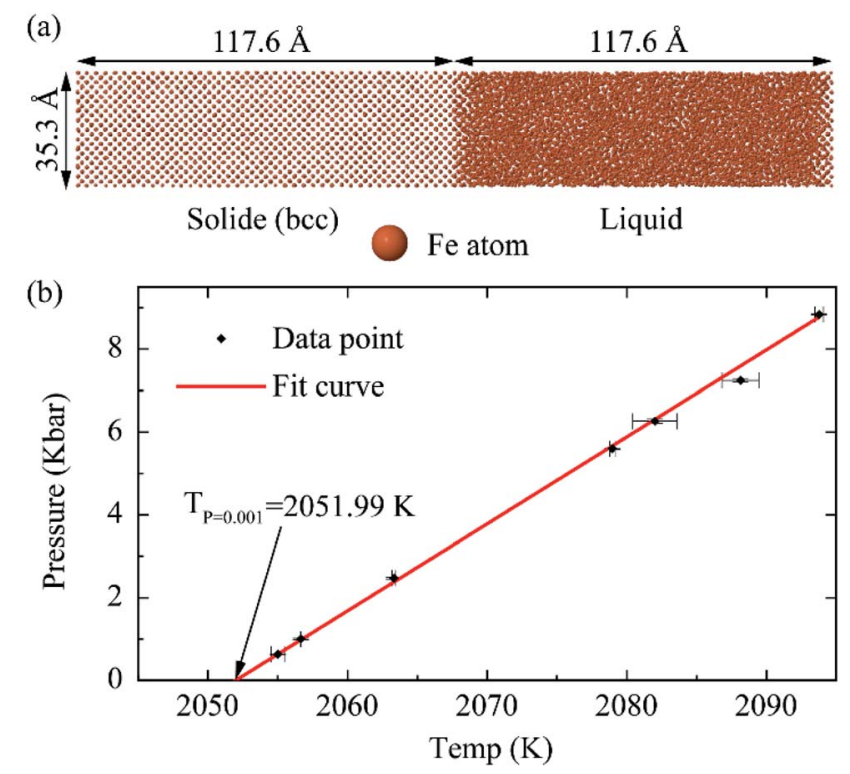

Fig. 1 The melting point was measured by solid-liquid coexistence method. (a) The establishment of the solid-liquid coexisting system on (100) crystal plane. (b) The relationship between pressure and corresponding melting point values under NVE condition. pressures were shown in Fig. 1(b). The $T_{\text {pot }}=2051.99 \mathrm{~K}$ was obtained by linear fitting under the pressure of $P=1$ bar.

The $T_{\mathrm{pot}}$ value was normalized to actual melting temperature in the simulation $\left(T_{\mathrm{s}}\right)$ using the following formula:

$$
T_{\mathrm{s}}=T_{\text {pot }} \times \frac{1873}{1811} \mathrm{~K}
$$

where $1811 \mathrm{~K}$ is the experimental value of pure Fe melting point, ${ }^{25} 1873 \mathrm{~K}$ is the actual melting temperature, so $T_{\mathrm{s}}=2122$ $\mathrm{K}$.

\subsection{The potential function verified by small $\mathrm{Ti}_{x} \mathrm{O}_{y}$ clusters}

The titanium atoms are substituted atoms ${ }^{26}$ and oxygen atoms ${ }^{27,28}$ are octahedral interstitial atoms in matrix iron. Different numbers of titanium and oxygen atoms were inserted into perfect bcc Fe supercell, and the geometrical structures of small (TiO) ${ }_{n}$ clusters were optimized using Fe-Ti-O potential. The energetically favored structures of $(\mathrm{TiO})_{n}(n \leq 3)$ are shown in Fig. 2(a)-(c). These structures of small (TiO) $)_{n}(n \leq 3)$ clusters are similar to those obtained using the first-principle method in our previous work. ${ }^{13}$

The atomic coordinates of $(\mathrm{TiO})_{n}$ clusters were extracted in Fig. 2(a)-(c), and then put in disordered molten iron for relaxation so as to verify the evolution of cluster at $2122 \mathrm{~K}$. We found that the two structures (TiO) $)_{1}$ and $(\mathrm{TiO})_{2}$ can exist stably in molten iron (shown in Fig. 2(d) and (e)). The structure (TiO) $)_{3}$ in Fig. 2(c) converts into a stereoscopic structure at $2122 \mathrm{~K}$ as shown in Fig. 2(f). We calculated the bond length of Ti-O, which is from $2.01 \AA$ to $2.19 \AA$. It is reasonable compared to the experiment value (1.96 ̊ (ref. 29)) in rutile.

The titanium and oxygen atoms in structures in Fig. 2(a)-(c) were restricted at substitutional sites and octahedral interstitial sites in iron lattice in perfect bcc Fe supercell. Whereas titanium and oxygen obtained sufficient kinetic energy from hightemperature environment, and the liquid iron in disordered state could not restrict titanium and oxygen atoms, the structure in Fig. 2(c) evolved into more stereoscopic structure in Fig. 2(f).

\subsection{Calculation process and analysis method}

As a result of low content of titanium and oxygen in steel, the probability of titanium and oxygen atoms collision in molten steel is low. If free titanium and oxygen atoms are inserted into iron matrix, they will form small size $\mathrm{Ti}_{x} \mathrm{O}_{y}$ clusters in a limited simulation scale. Experimental results of APT by Zhao Dan et al. ${ }^{12}$ showed that the ratio of Ti and $\mathrm{O}$ atoms is $1: 1$ in the structure of $\mathrm{Ti}_{x} \mathrm{O}_{y}$ clusters in steel. In this study, we inserted some pairs of $(\mathrm{TiO})_{1}$ structure instead of free titanium and oxygen atoms in molten iron.

The concentration of titanium and oxygen can influence the titanium oxide structure. Four systems with different titanium and oxygen contents (shown in Table 1) in molten iron were simulated. The concentrations of titanium and oxygen in group (a) are $199.9 \mathrm{ppm}$ and $66.1 \mathrm{ppm}$, respectively, similar with the parameters before deoxidation of titanium in actual steelmaking. The titanium and oxygen concentration in other three 
(a)

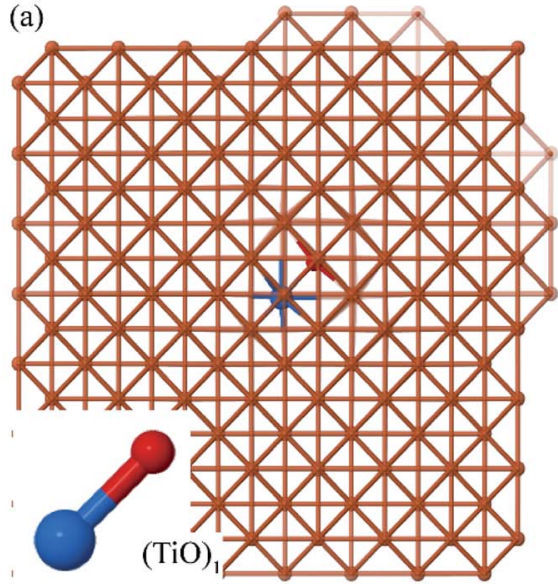

(d)

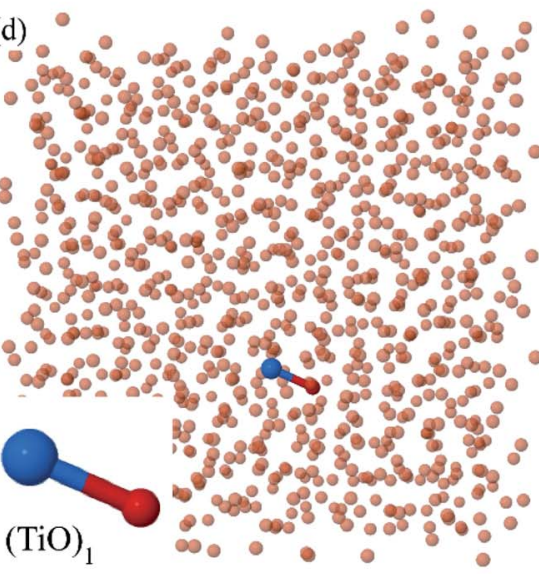

Fe atom (b)

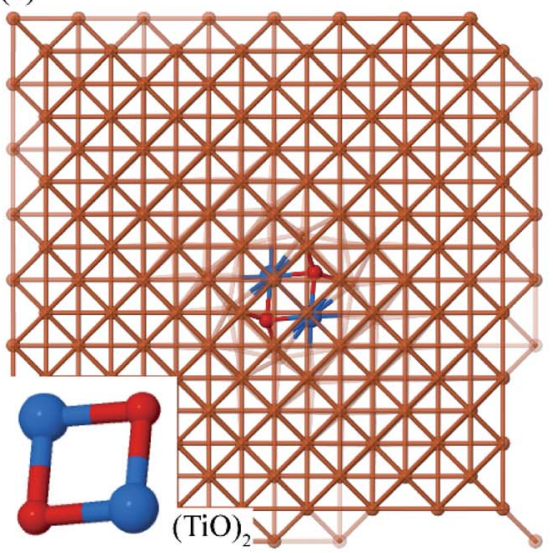

(c)

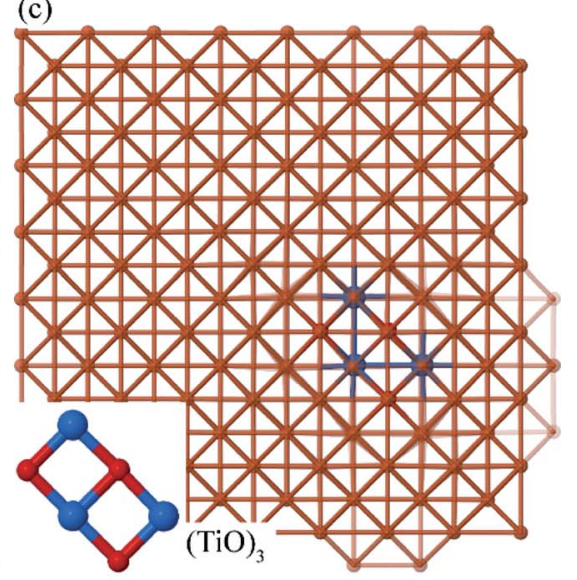

Small $(\mathrm{TiO})_{\mathrm{n}}$ cluster in iron matrix

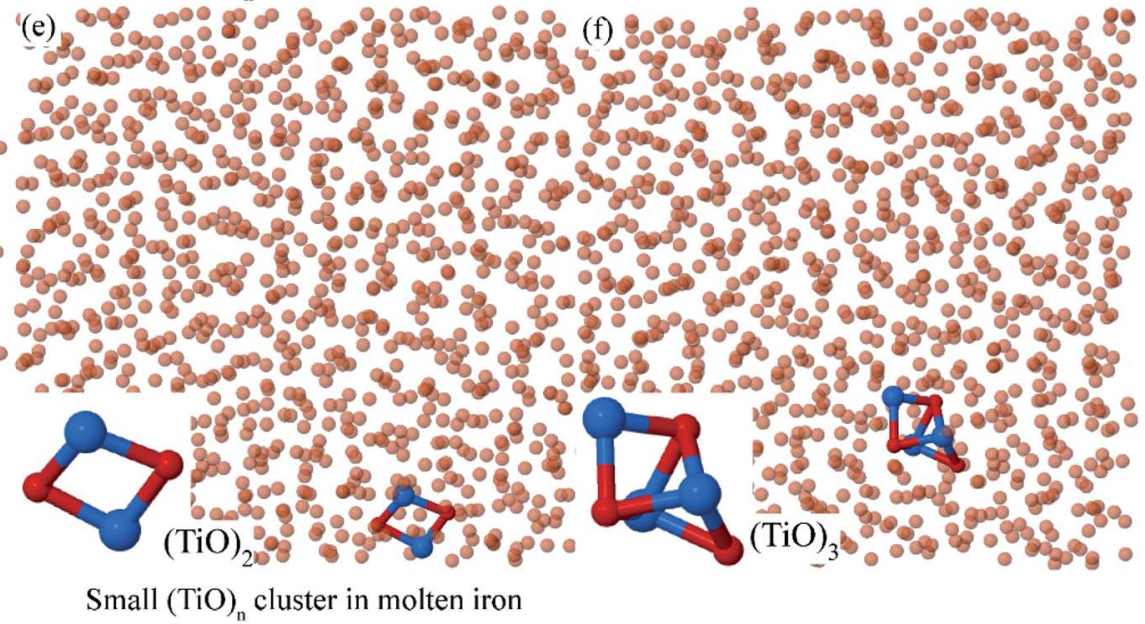

Small $(\mathrm{TiO})_{\mathrm{n}}$ cluster in molten iron

$\mathrm{O}$ atom

Fig. 2 Small (TiO) $)_{n}$ clusters were optimized in an $8 \times 8 \times 8$ iron supercell. (a) - (c) The $(\mathrm{TiO})_{n}$ cluster structure was established at $0 \mathrm{~K}$. (d) - (f) $(\mathrm{TiO})_{n}$ cluster structure was optimized at $T_{\mathrm{s}}=2122 \mathrm{~K}$.

groups are higher than those in actual production, but the maximum concentration is not more than $1 \%$.

Using PACKMOL, ${ }^{30}$ a package for building initial configurations in MD simulation, we constructed a $35 \times 35 \times 35$ supercell $(10.29 \mathrm{~nm} \times 10.29 \mathrm{~nm} \times 10.29 \mathrm{~nm})$. Iron atoms and $(\mathrm{TiO})_{1}$ structures (shown in Fig. 2(d)) distributed randomly in the supercell (shown in Fig. 3(a)). This periodic cell was relaxed for $0.01 \mathrm{~ns}$ at 0 to $2500 \mathrm{~K}$ to obtain overheating molten iron (hysteresis phenomenon $^{31}$ ). Subsequently, the cell was relaxed for $0.02 \mathrm{~ns}$ from 2500 to $T_{\mathrm{s}}=2122 \mathrm{~K}$. In the above two processes, the $(\mathrm{TiO})_{1}$ structures were fixed. Finally, the restriction on the $(\mathrm{TiO})_{1}$ structure was released, and the system was relaxed for 60

Table 1 The number of atoms in four systems

\begin{tabular}{|c|c|c|c|c|}
\hline & Group (a) & Group (b) & Group (c) & Group (d) \\
\hline Iron number & 85730 & 85550 & 85250 & 84750 \\
\hline$(\mathrm{TiO})_{1}$ number & 20 & 200 & 500 & 1000 \\
\hline
\end{tabular}

ns at $2122 \mathrm{~K}$, the pair distribution function of molten iron at $2122 \mathrm{~K}$ matched with the experiment. ${ }^{32}$ All these three processes were simulated with NVT ensemble. Fig. 3 shows the simulation details.

Since many atomic clusters were involved in the evolution process and it was difficult to manually count the numbers of clusters and atoms in simulation, we developed a computer algorithm to analyse the $\mathrm{Ti}_{x} \mathrm{O}_{y}$ clusters.

\section{Results and discussion}

\subsection{The growth of $\mathrm{Ti}_{x} \mathrm{O}_{y}$ cluster}

As has been known that, the stable structures of $\mathrm{Ti}_{x} \mathrm{O}_{y}$ clusters at high temperature is different from the cluster structures optimized at $0 \mathrm{~K}$ (discussed in Sec. 2.3). We inserted the molecular ion structure $(\mathrm{TiO})_{1}$ into molten iron and relaxed the $\mathrm{Fe}-\mathrm{Ti}-\mathrm{O}$ ternary system at $2122 \mathrm{~K}$. The aggregation process of $\mathrm{Ti}_{x} \mathrm{O}_{y}$ cluster in molten iron can be studied from the number of clusters and its time evolution. 
(a)
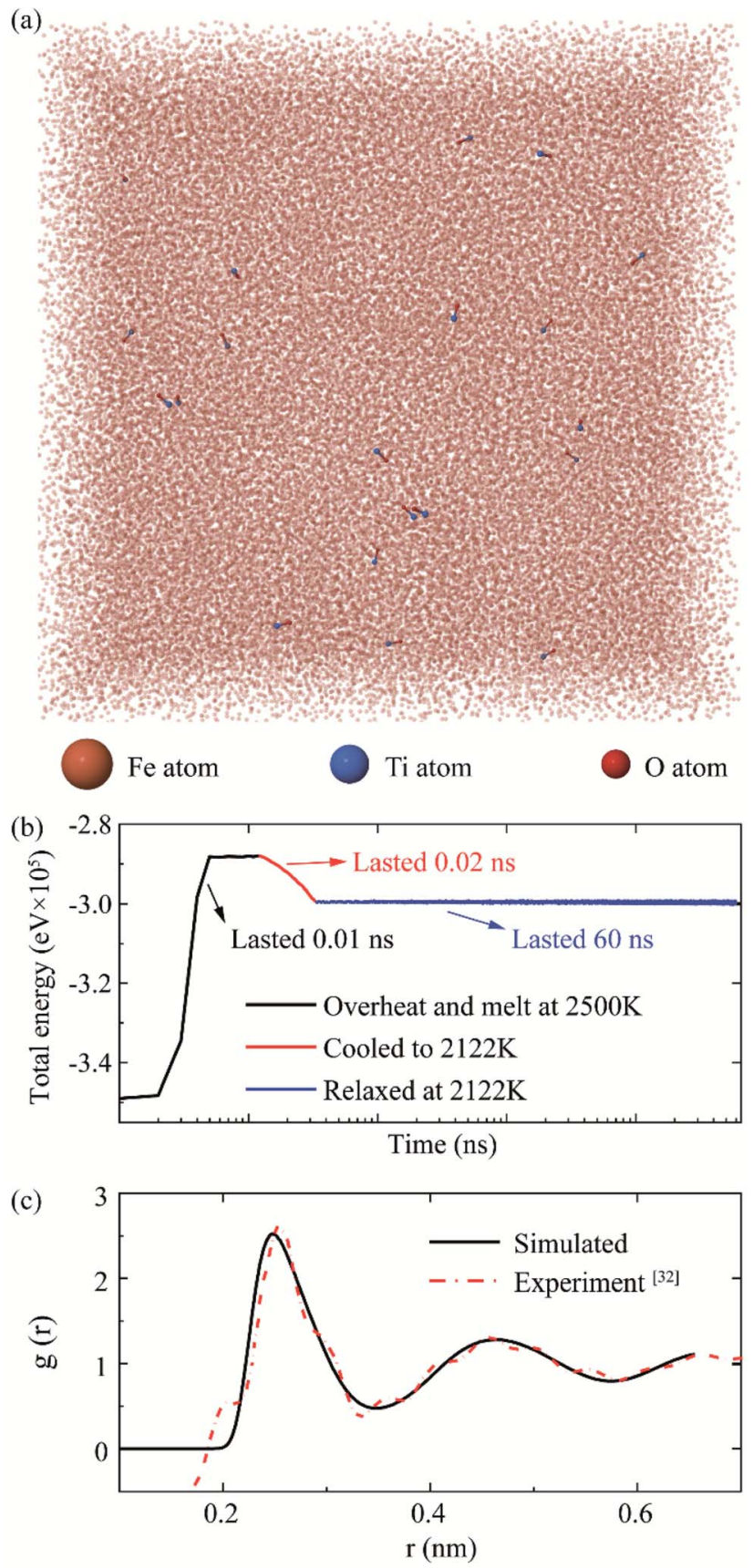

Fig. 3 The MD simulation process for $(\mathrm{TiO})_{1}$ structure in iron supercell. The group (a) in Table 1 as an example. (a) The atoms configurational snapshots before calculation. (b) The relationship between system total energy and time. (c) The pair distribution function of molten iron at $2122 \mathrm{~K}$.

In Fig. 4(a), in the first $1 \mathrm{~ns}$, the numbers of clusters $(N)$ decreased by 5, 141, 408 and 869 in groups (a), (b), (c) and (d), respectively. The $\mathrm{Ti}_{x} \mathrm{O}_{y}$ clusters aggregated to form larger clusters, resulting in a reduction in the number of clusters. From 10 $\mathrm{ns}$ to $60 \mathrm{~ns}$, the numbers of clusters decreased by $0.06,0.22,0.28$ and 0.4 clusters per nanosecond. The $\mathrm{Ti}_{x} \mathrm{O}_{y}$ cluster's aggregation rate was much slower in the $10-60 \mathrm{~ns}$ time range than that in the first $1 \mathrm{~ns}$. More particularly, the higher the concentration
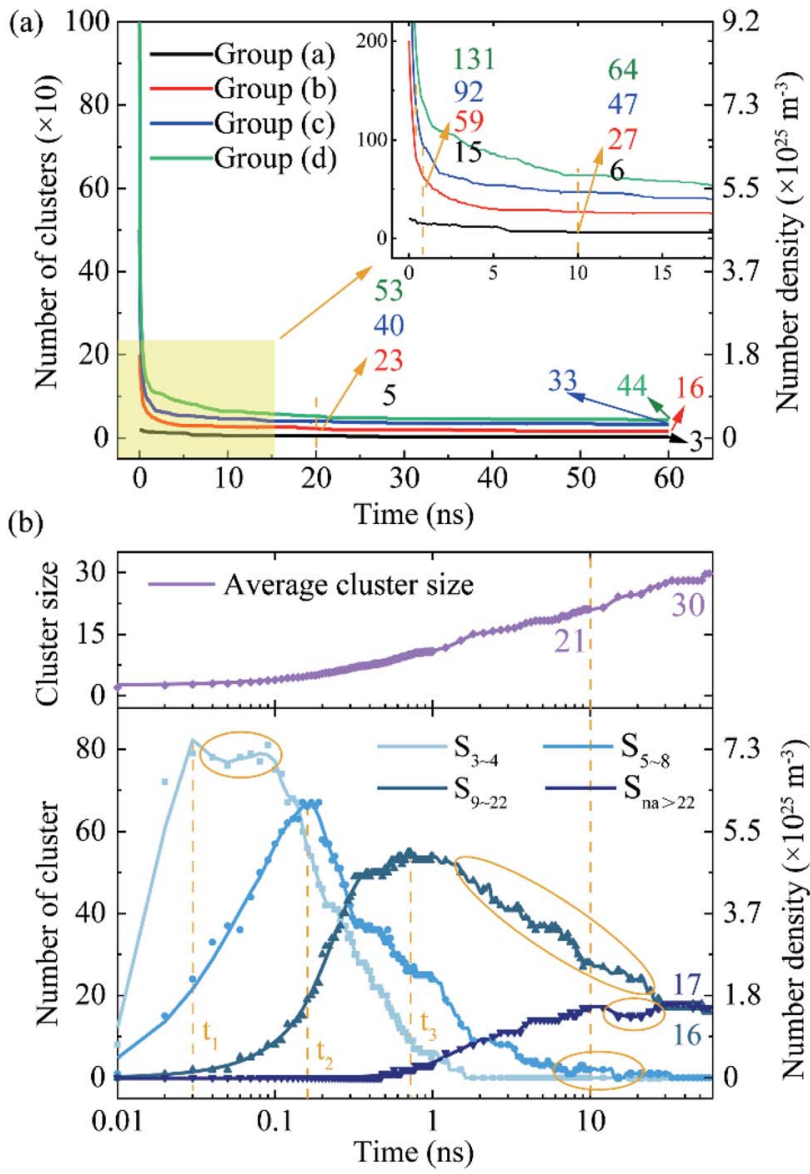

Fig. 4 The aggregation process of $\mathrm{Ti}_{x} \mathrm{O}_{y}$ clusters and $\mathrm{Ti}_{x} \mathrm{O}_{y}$ clusters size distribution. (a) The number of $\mathrm{Ti}_{x} \mathrm{O}_{y}$ clusters vs. time. Among the four colored curves, the initial number of clusters is 20,200, 500 and 1000 , respectively (shown in Table 1 ). (b) $\mathrm{Ti}_{x} \mathrm{O}_{y}$ clusters size distribution as a function of time. The dots represent the calculated data points while the lines represent smoothed fit to these values, $t_{1}(0.03 \mathrm{~ns}), t_{2}$ $(0.15 \mathrm{~ns})$ and $t_{3}(0.7 \mathrm{~ns})$ correspond to the time at the peak of cluster size.

of titanium and oxygen in molten iron, the faster the rate of cluster aggregation. Even though there coexists new clusters formation and cluster decomposition process, the above dynamic $\mathrm{Ti}_{x} \mathrm{O}_{y}$ clusters in molten iron grew rapidly at the beginning period and then grew steadily.

Fig. 4(b) combines the $\mathrm{Ti}_{x} \mathrm{O}_{y}$ clusters size distribution to analyse the clusters growth. We take group (c) as an example (blue curve in Fig. 4(a)). Group (c) has an appropriate number of titanium and oxygen atoms, and the cluster aggregation law is representative and applicable to other groups. The number density of clusters $\left(n_{\text {cluster }}\right)$ was obtained as the number of clusters divided by the simulation system volume $(V)$ :

$$
n_{\text {cluster }}=N / V
$$

We tracked the evolution of the $\mathrm{Ti}_{x} \mathrm{O}_{y}$ clusters, then counted the $\mathrm{Ti}_{x} \mathrm{O}_{y}$ cluster size distribution at different times. The cluster with $n$ atoms is denoted as $S_{n}$, the average cluster size ( $\left.C_{\text {avg_size }}\right)$ in molten iron was defined as follows: 


$$
C_{\text {avg_size }}=\mathrm{S}_{\text {total }} / N
$$

where $S_{\text {total }}$ is the number of atoms in all clusters, $N$ is the number of clusters. The number density of clusters is obtained by $n_{\text {cluster }}=\mathrm{S}_{n} / V$.

It was noteworthy that the curves show fluctuation (the yellow circle in Fig. 4(b)). As the energy fluctuates, the $\mathrm{Ti}_{x} \mathrm{O}_{y}$ clusters decompose to form small-sized clusters, indicating that there were decomposition and aggregation in unnucleated $\mathrm{Ti}_{x} \mathrm{O}_{y}$ clusters. The average size of the clusters constantly increased (the purple curve in Fig. 4(b)). With the formation of new cluster and cluster decomposition, the cluster grew toward larger dimensions.

The growth process of the $\mathrm{Ti}_{x} \mathrm{O}_{y}$ clusters can be restore from clusters size distribution (shown in Fig. 4(b)). The cluster size that appeared first was $\mathrm{S}_{3-4}$. The number of $\mathrm{Ti}_{x} \mathrm{O}_{y}$ clusters with size in range of $3 \leq n_{\mathrm{a}} \leq 4$ increased with time till reaching a limiting value at time $t_{1}=0.03 \mathrm{~ns}$ (see Fig. 4(b), $\mathrm{S}_{3-4}$ curve). With the advancing of time, the number of clusters $S_{3-4}$ was consumed and reduced and the number of clusters $S_{5-8}$ increased. As time process, the size distribution range became larger and larger, the number of small clusters decreased while the number of large clusters increased (see Fig. $4(\mathrm{~b}), \mathrm{S}_{5-8}$ and $\mathrm{S}_{9-}$ ${ }_{22}$ curve).

It should be mentioned that the large size $\mathrm{Ti}_{x} \mathrm{O}_{y}$ clusters needed a long time to grow up. As time processed, the number density of $\mathrm{Ti}_{x} \mathrm{O}_{y}$ clusters decreased which led to a decrease in the probability of cluster aggregation. It's worthwhile to further explore the growth path of $\mathrm{Ti}_{x} \mathrm{O}_{y}$ clusters before nucleation. We chose one of the $\mathrm{Ti}_{x} \mathrm{O}_{y}$ clusters at the end of simulation, then marked the titanium and oxygen atoms in this $\mathrm{Ti}_{x} \mathrm{O}_{y}$ cluster and reverse tracked the atomic trajectory to obtain the atomic coordinates of the labeled atoms, we could ascertain the way of $\mathrm{Ti}_{x} \mathrm{O}_{y}$ cluster growth. This method was implemented in the open visualization tool OVITO $^{33}$ package. The results were shown in Fig. 5.

It can be seen from Fig. 5 that there were some small $\mathrm{Ti}_{x} \mathrm{O}_{y}$ clusters containing a large number of labeled titanium and oxygen atoms at $1 \mathrm{~ns}$ (see Fig. 5(b)(1) and (2)). These $\mathrm{Ti}_{x} \mathrm{O}_{y}$ clusters collided together in molten iron and formed bigger clusters at $10 \mathrm{~ns}$. The process of collision between two clusters was shown in Fig. 5(c).

Some $\mathrm{Ti}_{x} \mathrm{O}_{y}$ clusters contained a small number of labeled oxygen atoms (yellow balls in the unlabeled clusters in Fig. 5(b)(3)-(5). The labeled $\mathrm{Ti}_{x} \mathrm{O}_{y}$ clusters also contained a small number of unlabeled oxygen atoms (red balls in the labeled clusters Fig. 5(b)(6) and (c)). These oxygen atoms might detach from the labeled $\mathrm{Ti}_{x} \mathrm{O}_{y}$ clusters after a period of movement and merged into other $\mathrm{Ti}_{x} \mathrm{O}_{y}$ clusters or into molten iron. $\mathrm{Ti}_{x} \mathrm{O}_{y}$ clusters would compete with iron and other $\mathrm{Ti}_{x} \mathrm{O}_{y}$ structures to absorb oxygen atoms. This phenomenon indicates that the $\mathrm{Ti}_{x} \mathrm{O}_{y}$ clusters will adjust the structure due to energy fluctuations before nucleation.

Collision is the fastest way for clusters to grow up, but it is limited by the density of clusters, which affects the collision probability. The dissociation of oxygen atoms can lead to positive growth and negative growth of $\mathrm{Ti}_{x} \mathrm{O}_{y}$ clusters. Zhang et al. ${ }^{34}$ calculated the process of nucleation of primary inclusion and found that the collision make a huge contribution to cluster growth when the cluster size is less than $10 \mathrm{~nm}$.

\subsection{Morphology evolution of $\mathrm{Ti}_{x} \mathrm{O}_{y}$ clusters}

The process of cluster aggregation and growth becomes clear according to the above discussion. The $\mathrm{Ti}_{x} \mathrm{O}_{y}$ clusters were classified according to the number of titanium and oxygen atoms at $t_{1}=0.03 \mathrm{~ns}, t_{2}=0.15 \mathrm{~ns}$ and $t_{3}=0.7 \mathrm{~ns}$ in group (c) (peak position of $\mathrm{S}_{3-4}, \mathrm{~S}_{5-8}$ and $\mathrm{S}_{9-22}$ in Fig. 4, respectively). We counted the number of different types of $\mathrm{Ti}_{x} \mathrm{O}_{y}$ clusters and found that $\mathrm{Ti}_{x} \mathrm{O}_{y}$ clusters with a stoichiometric $\mathrm{Ti}: \mathrm{O}$ ratio of $1: 1$ occupied the majority of all clusters. The proportion of $(\mathrm{TiO})_{n}(n \leq 11, \mathrm{Ti}: \mathrm{O}=1: 1)$ clusters were listed in Table 2 . The evolution process of $\mathrm{Ti}_{x} \mathrm{O}_{y}$ cluster structure was explored by comparing the change of cluster proportion.

It has been found that the $(\mathrm{TiO})_{n}(2 \leq n \leq 6)$ accounted for the majority at the peak $\mathrm{Ti}_{x} \mathrm{O}_{y}$ clusters size distribution. We have extracted the atomic coordinates of the $(\mathrm{TiO})_{n}(2 \leq n \leq 6)$ clusters in Fig. 6 to show the cluster structures.

The structures of $(\mathrm{TiO})_{2}$ and $(\mathrm{TiO})_{3}$ were the same as discussed in 2.3 Section. The structure of $(\mathrm{TiO})_{4}$ was the first complete cubic-like structure. When $n=5$, $(\mathrm{TiO})_{5}$ and $(\mathrm{TiO})_{5}^{\prime}$ clusters coexisted in molten iron. The energy of the (TiO) $)_{5}^{\prime}$ structure was $2.81 \mathrm{eV}$ higher than that of $(\mathrm{TiO})_{5}$ structure. This proved that $(\mathrm{TiO})_{5}$ was more stable than $(\mathrm{TiO})_{5}^{\prime}$. When $n \geq 6$, the $(\mathrm{TiO})_{n}$ clusters would evolve to chain-like structures (as shown in Fig. 5(b) and (c)).

Xiang et al. ${ }^{35}$ obtained two types of (TiO) ${ }_{n}$ clusters using the $a b$ initio calculations: cubic-like structure and ring-like structure. They found that the ring-like structures are more stable than cubic-like structures as the size of clusters increasing. The cluster structures in Fig. 6 were similar to the cubic-like structure showed in Xiang's result. ${ }^{35}$ With the effect of high temperature and iron atoms, the cubic-like structure was easier to form than the ring-like structure when $n<6$.

Fig. 7 shows the atomic coordinates after the energy minimization. Comparing the four images, the difference in the concentration of titanium and oxygen atoms affects the amount and size of the $\mathrm{Ti}_{x} \mathrm{O}_{y}$ clusters. But there is not much difference in cluster structure. Where the structures of $\mathrm{Ti}_{x} \mathrm{O}_{y}$ clusters are mostly chain-like as shown in Fig. 7(2), (3), (5), (7) and (8), branched structure as shown in Fig. 7(4) and (9), cubic-like structure as shown in Fig. 7(1) and (6). The length of the longest cluster (6) is about $5 \mathrm{~nm}$, and the length of other clusters are about $0.5 \mathrm{~nm}$ to $3 \mathrm{~nm}$. Demichelis ${ }^{36}$ observed stable prenucleation clusters from early stages of calcium carbonate formation, the prenucleation clusters consist of chains, branches and rings, which can fold and coil like a polymer. But we did not find the folding phenomenon of chain-like or branched structures in molten iron.

\subsection{Effect of molten iron on $\mathrm{Ti}_{x} \mathrm{O}_{y}$ clusters structure}

Many researchers studied the structural evolution process of particles, ignoring the influence of environment. But the influence of the matrix on the cluster structure cannot be 
(a)
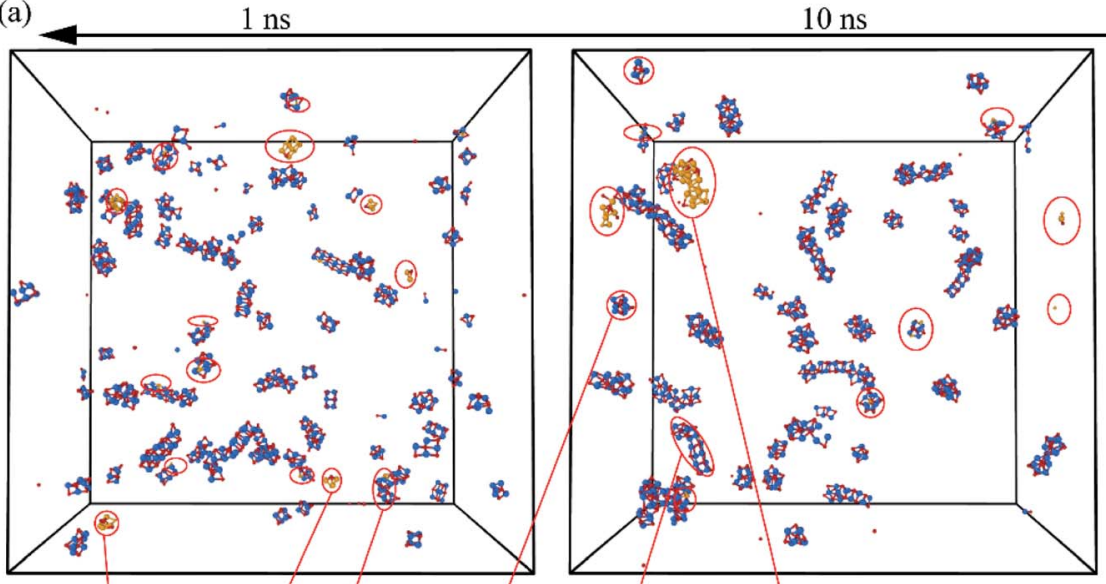

(c)

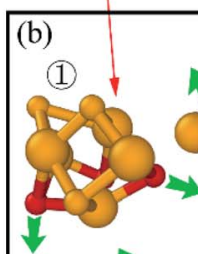

(3)

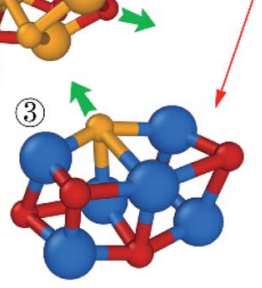

(2) (4)

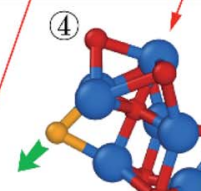

(5)

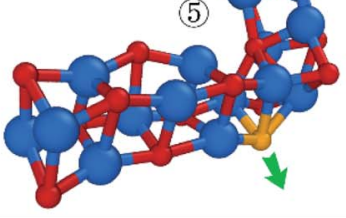

$60 \mathrm{~ns}$

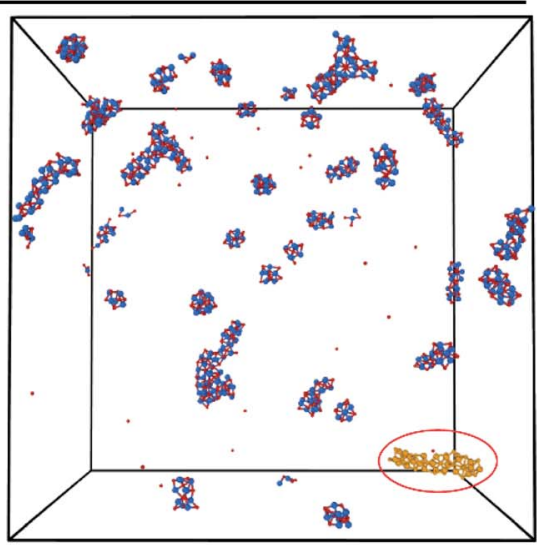

Unlabeled $\mathrm{Ti}$ atom

Unlabeled $\mathrm{O}$ atom

Labeled Ti atom

Labeled $\mathrm{O}$ atom

Escape oxygen atom

Fig. 5 Growth process of the $\mathrm{Ti}_{x} \mathrm{O}_{y}$ clusters. (a) Simulation cell, iron atoms were hidden. The labeled titanium and oxygen atoms (in red circles) at $1 \mathrm{~ns}$ and $10 \mathrm{~ns}$ formed a labeled $\mathrm{Ti}_{x} \mathrm{O}_{y}$ cluster (in red circle) at $60 \mathrm{~ns}$. (b) Part of clusters were enlarged which contain the labeled atoms. The green arrow indicates the oxygen atom will escape from the cluster. (c) The process of collision and merging of labeled clusters. Lots of chain-like Ti $\mathrm{O}_{y}$ cluster structure can be find in molten iron, we discussed this phenomenon in Sections 3.2 and 3.3.

ignored. To find out the effect of molten iron on the structure of $\mathrm{Ti}_{x} \mathrm{O}_{y}$ clusters, we extracted some chain-like and branched structure's (shown in Fig. 7) atomic coordinates to explore their optimal structures without iron atoms at $2122 \mathrm{~K}$. We examined plenty of clusters and displayed typical structural evolutions in Fig. 8.

Table 2 The percentage of $(\mathrm{TiO})_{n}$ cluster numbers at the peak of $\mathrm{S}_{3-4}$, $\mathrm{S}_{5-8}$ and $\mathrm{S}_{9-22}$ on $t_{1}=0.03 \mathrm{~ns}, t_{2}=0.15 \mathrm{~ns}$ and $t_{3}=0.7 \mathrm{~ns}$, respectively. The 'Others' represents the $\mathrm{Ti}: \mathrm{O}$ does not equal to $1: 1$ in $\mathrm{Ti}_{x} \mathrm{O}_{y}$ clusters

\begin{tabular}{|c|c|c|c|}
\hline Time & $t_{1}$ & $t_{2}$ & $t_{3}$ \\
\hline$(\mathrm{TiO})_{2} \mathrm{Pct}$ & 74 & 41 & 9 \\
\hline$(\mathrm{TiO})_{3} \mathrm{Pct}$ & 18 & 28 & 12 \\
\hline$(\mathrm{TiO})_{4}$ Pct & 5 & 16 & 12 \\
\hline$(\mathrm{TiO})_{5}$ Pct & 2 & 8 & 21 \\
\hline$(\mathrm{TiO})_{6} \mathrm{Pct}$ & $\mathrm{N}$ & 1 & 11 \\
\hline$(\mathrm{TiO})_{7} \mathrm{Pct}$ & $\mathrm{N}$ & 1 & 8 \\
\hline$(\mathrm{TiO})_{8}$ Pct & $\mathrm{N}$ & $\mathrm{N}$ & 4 \\
\hline$(\mathrm{TiO})_{9}$ Pct & $\mathrm{N}$ & 1 & 1 \\
\hline$(\mathrm{TiO})_{10} \mathrm{Pct}$ & $\mathrm{N}$ & $\mathrm{N}$ & 1 \\
\hline$(\mathrm{TiO})_{11}$ Pct & $\mathrm{N}$ & $\mathrm{N}$ & 4 \\
\hline Others Pct & 1 & 4 & 17 \\
\hline
\end{tabular}

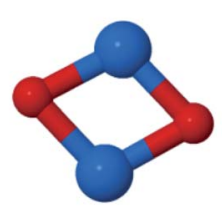

$(\mathrm{TiO})_{2}$

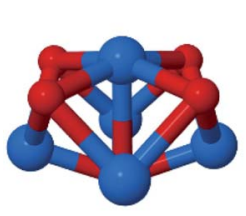

$(\mathrm{TiO})_{5}$

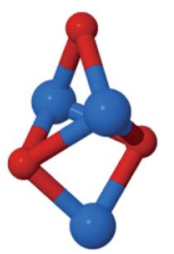

$(\mathrm{TiO})_{3}$

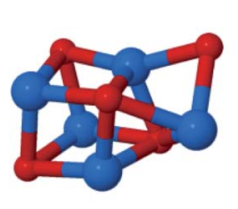

(TiO)

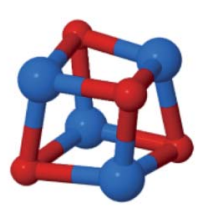

$(\mathrm{TiO})_{4}$

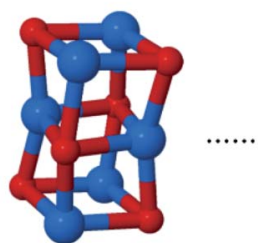

$(\mathrm{TiO})_{6}$
Ti atom

$\mathrm{O}$ atom

Fig. 6 The $(\mathrm{TiO})_{n}(2 \leq n \leq 6)$ cluster structures extracted from molten iron.

The 'branch' and the 'chain' in $\mathrm{Ti}_{x} \mathrm{O}_{y}$ clusters folded without iron atoms obstruction, and evolved into near-spherical or cage structures. These chain-like and branched structures can be 


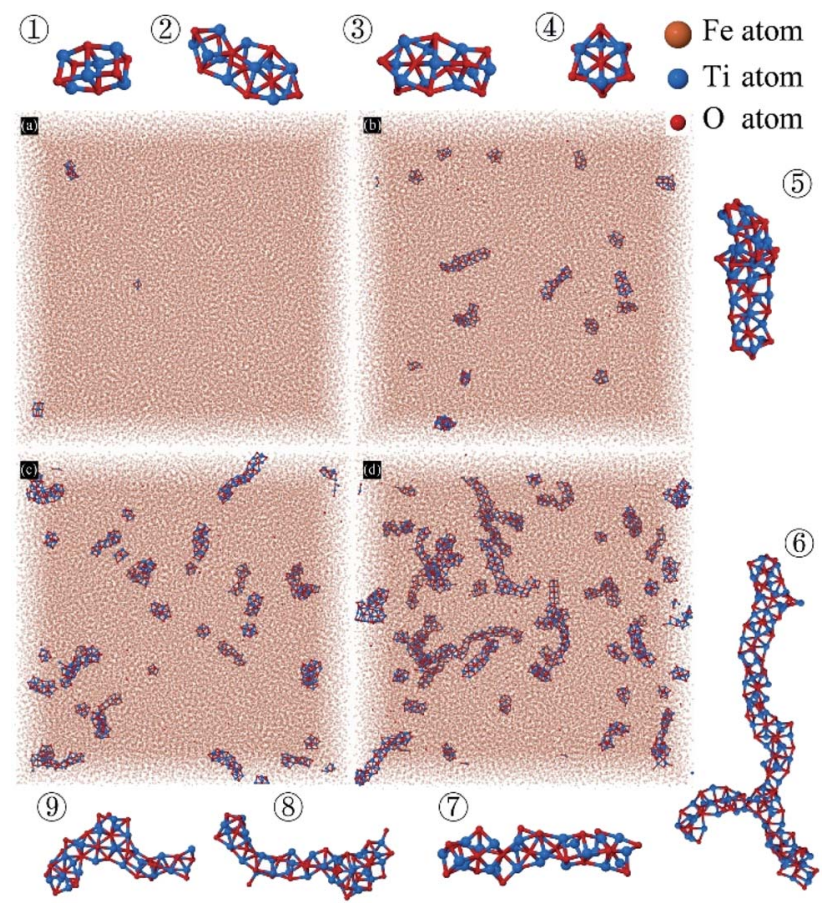

Fig. 7 Atomic coordinates snapshots in simulation box after energy minimization and typical species of TiO structures observed in simulation. (a)-(d) Correspond to systems with different concentration of Ti and $O$ corresponding to Table 1. Illustration (1)-(9) are some typical cluster structures observed in the system.

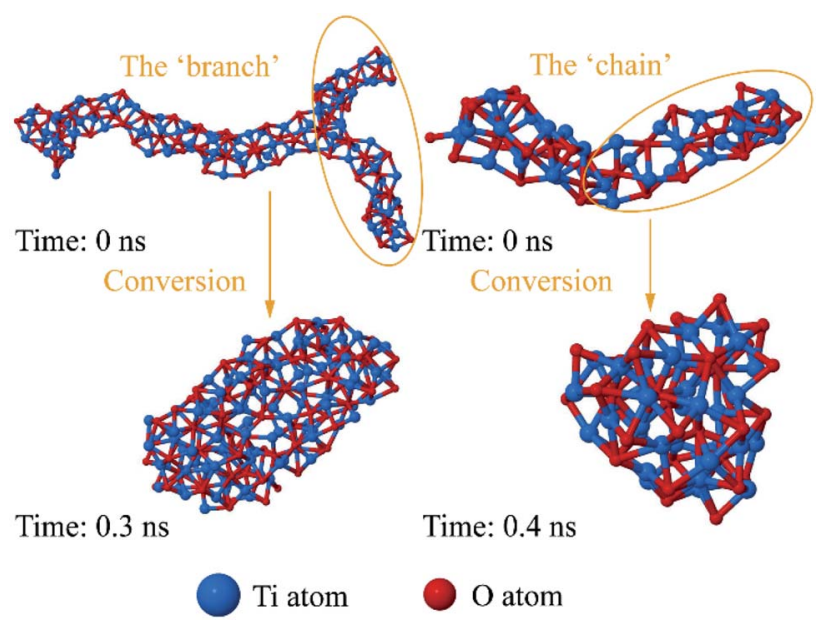

Fig. 8 The evolution of chain-like and branched clusters in the absence of iron atoms.

regarded as dynamic structure. The dynamic structures can constantly evolve but the iron atoms hindered the structures from folding and coiling. It is possible that the interactions between $\mathrm{Fe}^{-\mathrm{Ti}^{37,38}}$ and $\mathrm{Fe}-\mathrm{O}^{39}$ makes titanium and oxygen atoms difficult to move freely, which can be seen from the interfacial energy between $\mathrm{Fe}$ and $\mathrm{Ti}_{x} \mathrm{O}_{y}$ clusters. As for how these chainlike structures grow to form critical nuclei in molten steel, the question remains to be further studied.

\section{Conclusions}

The formation of $\mathrm{Ti}_{x} \mathrm{O}_{y}$ clusters before nucleation is clarified by MD simulations of the Fe-Ti-O system in the actual smelting process for up to $60 \mathrm{~ns}$. The structure of small (TiO) $)_{n}$ clusters obtained by MD was compared with the results of firstprinciples calculation, ensuring the applicability of the atomic interaction potential. Fe-Ti-O system with titanium concentrations between $0.02 \%$ and $1.00 \%$ was simulated to prove that the concentration will affect $\mathrm{Ti}_{x} \mathrm{O}_{y}$ cluster aggregation rate and size. Visual inspection, cluster identification and reverse tracking of the atomic trajectory were employed to explore the growth process and morphology evolution of $\mathrm{Ti}_{x} \mathrm{O}_{y}$ cluster before nucleation. The detailed conclusions are as follow:

(1) $\mathrm{Ti}_{x} \mathrm{O}_{y}$ clusters appear a size distribution variation with time, clusters of a certain size are dominant during a certain amount of time, as time process, the size of the largest number of clusters will become larger. As the energy fluctuates, a part of $\mathrm{Ti}_{x} \mathrm{O}_{y}$ cluster will decompose into small clusters, but average cluster size keeps increasing.

(2) Collision is the main way for $\mathrm{Ti}_{x} \mathrm{O}_{y}$ cluster to grow up in molten iron, in the meantime, oxygen atoms will detach from the $\mathrm{Ti}_{x} \mathrm{O}_{y}$ cluster or merge into another $\mathrm{Ti}_{x} \mathrm{O}_{y}$ cluster due to the competition between iron and titanium atoms.

(3) When the number of atoms in $\mathrm{Ti}_{x} \mathrm{O}_{y}$ clusters is greater than 3 but less than 12 , cluster structure with Ti to $\mathrm{O}$ stoichiometric ratio of $1: 1$ holds the largest proportion, which are cubic-like structure.

(4) When $\mathrm{Ti}_{x} \mathrm{O}_{y}$ cluster grows, larger cluster has a dynamic chain structure. The 'chain' or 'branch' structure in $\mathrm{Ti}_{x} \mathrm{O}_{y}$ cluster will fold and coil without the influence of molten iron, and evolved into near-spherical or cage structures.

\section{Conflicts of interest}

We declare that we do not have any commercial or associative interest that represents a conflict of interest in connection with this work.

\section{Acknowledgements}

This work is supported by Open Project of State Key Laboratory of Advanced Special Steel, Shanghai University. We also thank High Performance Computing Center, Shanghai University for the technical support. The authors would like to express gratitude to Prof. Yongquan $\mathrm{Wu}$ for the valuable discuss and suggestions.

\section{Notes and references}

1 J. I. Takamura and S. Mizoguchi, The Sixth International Iron and Steel Congress, Nagoya, 1990, vol. 5.

2 L. Huigai, W. Chunfeng, Z. Dan, Z. Shaobo and Z. Qijie, Shanghai Met., 2011, 33, 36-39.

3 C. C. Zheng, X. M. Wang, S. R. Li, C. J. Shang and X. L. He, Sci. China: Technol. Sci., 2012, 55, 1556-1565.

4 J. H. Park, Calphad, 2011, 35, 455-462. 
5 W. Z. Mu, P. G. Jonsson and K. Nakajima, J. Mater. Sci., 2016, 51, 2168-2180.

6 A. F. Wallace, L. O. Hedges, A. Fernandez-Martinez, P. Raiteri, J. D. Gale, G. A. Waychunas, S. Whitelam, J. F. Banfield and J. J. De Yoreo, Science, 2013, 341, 885-889. 7 W. Masamitsu and S. Nobuo, ISIJ Int., 2007, 47, 627.

8 K. Wasai and K. Mukai, Metall. Mater. Trans. B, 1999, 30, 1065-1074.

9 G. C. Wang, Q. Wang, S. L. Li, X. G. Ai and D. P. Li, Acta Metall. Sin., 2015, 28, 272-280.

10 G. C. Wang, Q. Wang, S. L. Li, X. G. Ai and C. G. Fan, Sci. Rep., 2014, 4, 5082.

11 N. Zong, Y. Liu and P. He, RSC Adv., 2015, 5, 48382-48390.

12 D. Zhao, W. Q. Bao, H. G. Li, S. B. Zheng and K. C. Chou, J. Alloys Compd., 2018, 744, 797-800.

13 W. Q. Bao, W. Zhang, H. G. Li, S. B. Zheng and Q. J. Zhai, RSC Adv., 2017, 7, 52296-52303.

14 T. Albaret, F. Finocchi and C. Noguera, Appl. Surf. Sci., 1999, 144-45, 672-676.

15 Z.-w. Qu and G.-J. Kroes, J. Phys. Chem. C, 2007, 111, 1680816817.

16 W. Meng-Hsiung, C. Chuan and J. Shin-Pon, Chin. J. Catal., 2009, 30, 384-390.

17 O. L. G. Alderman, L. B. Skinner, C. J. Benmore, A. Tamalonis and J. K. R. Weber, Phys. Rev. B: Condens. Matter Mater. Phys., 2014, 90, 094204.

18 S. Plimpton, Fast Parallel Algorithms for Short-Range Molecular Dynamics, 1995.

19 W. J. Joost, S. Ankem and M. M. Kuklja, Modell. Simul. Mater. Sci. Eng., 2014, 23, 015006.

20 J. Pencer, E. Torres, J. Alexander and D. D. Radford, Comput. Mater. Sci., 2016, 125, 110-116.

21 X. W. Zhou and H. N. G. Wadley, J. Phys.: Condens. Matter, 2005, 17, 3619-3635.

22 B. Jeon, S. K. Sankaranarayanan and S. Ramanathan, J. Phys. Chem. C, 2011, 115, 6571-6580.
23 F. Streitz and J. Mintmire, J. Adhes. Sci. Technol., 1994, 8, 853-864.

24 J. R. Morris and X. Song, J. Chem. Phys., 2002, 116, 93529358.

25 J. P. Kruth, L. Froyen, J. Van Vaerenbergh, P. Mercelis, M. Rombouts and B. Lauwers, J. Mater. Process. Technol., 2004, 149, 616-622.

26 Y. Jiang, J. R. Smith and G. R. Odette, Phys. Rev. B: Condens. Matter Mater. Phys., 2009, 79, 064103.

27 A. Claisse and P. Olsson, Nucl. Instrum. Methods Phys. Res., Sect. B, 2013, 303, 18-22.

28 Y. Wang, Z. Pan, Y. Ho, Y. Xu and A. Du, Nucl. Instrum. Methods Phys. Res., Sect. B, 2001, 180, 251-256.

29 O. Alderman, L. Skinner, C. Benmore, A. Tamalonis and J. Weber, Phys. Rev. B: Condens. Matter Mater. Phys., 2014, 90, 094204.

30 L. Martínez, R. Andrade, E. G. Birgin and J. M. Martínez, J. Comput. Chem., 2009, 30, 2157-2164.

31 S. Z. Chavoshi, S. Z. Xu and S. Goel, Proc. R. Soc. A, 2017, 473, 20170084.

32 Z. Qijie, Fundamentals of structure refinement technology for metal solidification, Science Press, China, 2018, pp. 9-11.

33 A. Stukowski, Modell. Simul. Mater. Sci. Eng., 2010, 18, 21542162.

34 L. Zhang, W. Pluschkell and B. G. Thomas, Nucleation and growth of alumina inclusions during steel deoxidation, 85th Steelmaking Conference, 2002, vol. 85, pp. 463-476.

35 J. Xiang, X. Yan, Y. Xiao, Y. Mao and S. Wei, Chem. Phys. Lett., 2004, 387, 66-69.

36 R. Demichelis, P. Raiteri, J. D. Gale, D. Quigley and D. Gebauer, Nat. Commun., 2011, 2, 590.

37 A. Sutton and W. Hume-Rothery, The London, Edinburgh, and Dublin Philosophical Magazine and Journal of Science, 1955, 46, 1295-1309.

38 J. L. Murray, Bull. Alloy Phase Diagrams, 1981, 2, 320-334.

39 J. Byggmästar, M. Nagel, K. Albe, K. Henriksson and K. Nordlund, J. Phys.: Condens. Matter, 2019, 31(21), 215401. 